See discussions, stats, and author profiles for this publication at: https://www.researchgate.net/publication/263378403

\title{
Serial vs. divergent supply chain networks: A comparative analysis of the bullwhip effect
}

Article in International Journal of Production Research · April 2014

DOI: 10.1080/00207543.2013.860495

\section{CITATIONS}

36

3 authors:

Roberto Dominguez

Universidad de Sevilla

31 PUBLICATIONS 278 CITATIONS

SEE PROFILE

Salvatore Cannella

University of Catania

68 PUBLICATIONS 966 CITATIONS

SEE PROFILE

\section{READS}

989

Jose M. Framinan

Universidad de Sevilla

197 PUBLICATIONS 3,474 CITATIONS

SEE PROFILE

Some of the authors of this publication are also working on these related projects:

Collaboration strategies in decentralized supply chains with partial information sharing View project

Logistics and Supply Chain View project 


\title{
Serial versus divergent supply chain networks: a comparative analysis of the bullwhip effect
}

\author{
Roberto Dominguez ${ }^{1}$, Jose M. Framinan ${ }^{2}$, Salvatore Cannella ${ }^{3}$ \\ ${ }^{1}$ Industrial Management, School of Engineering, University of Seville, Ave. Descubrimientos \\ s/n, Seville, E41092, Spain; tel: (+34) 954488137; e-mail: rdc@us.es (corresponding author) \\ ${ }^{2}$ Industrial Management, School of Engineering, University of Seville, Ave. Descubrimientos \\ s/n, Seville, E41092, Spain; tel: (+34) 954487214; e-mail: framinan@us.es \\ ${ }^{3}$ tel: (+39) 3386263359; e-mail: salvatore.cannella@ ist.utl.pt
}

\begin{abstract}
The amplification of demand variation in a supply chain network (SCN) is a well-known phenomenon called the bullwhip effect, which creates inefficiencies due to high variation in the order quantities placed between companies, leading to a flow of a larger number of units than the actual need, increasing stock and generating stock-outs. Since this phenomenon has been recognized as one of the main obstacles for improving SCN performance, recently it has received a lot of attention by SCN managers and researchers. One of the most common simplifying assumptions in the literature is to assume that the SCN adopts a serial structure. The present work addresses a comparative analysis of the bullwhip effect between a serial SCN and a more complex divergent SCN. To do so, we adopt the framework proposed by Towill et al. (2007), and analyze the response of both SCNs under two different input demands: a stationary demand and an impulse demand. The results reveal that there are not significant differences in terms of bullwhip effect between both SCNs for a stationary demand. Nevertheless, we show how for a violent disturbance in customer demand there is a great different between the two SCNs.
\end{abstract}

Keywords: Bullwhip Effect, Serial Supply Chain, Divergent Supply Chain, Simulation, Multi-Agent Systems, Shock Behavior.

\section{Published in:}

International Journal of Production Research, 52 (7), pp. 2194-2210. 2014.

doi: 10.1080/00207543.2013.860495 


\section{Introduction}

The amplification of demand variation in a Supply Chain Network (SCN) is called the bullwhip effect (Lee et al., 1997), and it can be defined as the tendency to see an increase in variability in the replenishment orders with respect to the true demand due to distortion in the demand information as we move upstream in the SCN (Nepal et al., 2012). As consequence, orders placed by upstream nodes exhibit a higher variability as compared to that of orders placed by their downstream partners (Chatfield and Pritchard, 2013). This phenomenon has many undesirable effects such as increasing stock and generating stock-outs (Adenso-Diaz et al., 2012).

The bullwhip effect is relevant both for individual companies that face an unnecessarily variable demand as well as for the entire SCN (Zotteri, 2012). Moreover, the most recent economic downturn has no doubt created a lot of bullwhips around the world (Lee, 2010). For instance, the electronics manufacturing sector has experienced something akin to the bullwhip effect in terms of larger sales declines occurring further upstream (Dvorak, 2009). More specifically, in the last quarter of 2008, consumer demand had declined 8 percent, while product shipments fell 10 percent and chip sales fell 20 percent. These data suggest that electronics retailers, wholesalers and manufacturers responded differently to the decline in consumer demand (Dooley et al., 2010).

Since the bullwhip effect has been long recognized as one of the main obstacles for improving the performance of a SCN, it has received in the last years a lot of attention by managers and researchers (Li, 2012). More specifically, several studies have been generated in the last decade to better understand the causes, economics consequences and remedies to the bullwhip effect. In order to analyze this phenomenon under real business world conditions, increasingly complex mathematical representations of SCNs (such as multi-product scenarios, stochastic lead times, production/distribution capacity constraints, reverse logistic and so on) have been developed. However, several assumptions are commonly made to simplify the analysis (Chatfield and Pritchard, 2013), being one of the most relevant what it can be labeled as a "serial structure model", i.e. each echelon $k$ in the system has a single successor $k+1$ and a single predecessor $k-1$. Undoubtedly, the serial SCN system analysis has represented and continues to represent a powerful technique for studying the dynamics of the bullwhip effect, but this assumption is seldom verified in real SCNs (Bhattacharya and Bandyopadhyay, 2011). The main reason for the adoption of this modeling structure is probably due to the fact that most of the studies dealing with supply chain dynamics are based on classical operational 
research methods, continuous time differential equation models, and discrete time difference equation models. Classical operational research methods approaches are not always able to cope with the characteristics of dynamics SCNs (Riddalls et al., 2000; Long et al., 2011). Analogously, continuous time and discrete time difference equation models are not always suitable for analyzing complex supply chain structures outside the serial supply chain, given the high order of differential equations (one tier generally gives a 2nd-4th order system; 2 tiers even 2nd-6th order), which makes analytical analysis difficult (Holweg and Disney, 2005). Essentially, due to the complexity and mathematical intractability of multi-echelon systems, the majority of the literature tends to focus on serial two-echelon systems (Hwarng, 2005).

Nowadays, the increasing challenges of the new generation of SCNs such as those mentioned in Butner (2010), Christopher and Holweg (2011), and Stank et al. (2011), require more realistic models to analyze the increasing complexity of those structures. Hence, there is a need to assess the dynamics of SCNs characterized by more than one member in the same echelon of the chain (Moser et al., 2011; Xuan et al., 2011; Ma et al., 2013). More specifically, in this work we address one of most common adopted SCN structures in the real world, i.e. the divergent or arborescent SCN (Beamon and Chen, 2001). Mineral industries and in general consumer-oriented industries, such as cell phone manufacturers, often adopt this typology of SCN (Hung, 2011). This structure is characterized by a tree-like structure, where every stock point in the system receives supply from exactly one higher echelon stock point, but can supply to one or more lower echelon stock points (Ganeshan, 1999; Hwarng et al., 2005).

The aim of this paper is to analyze the bullwhip effect of a complex SCN. To do so, we perform a comparative analysis between a classical serial SCN with a more complex (divergent) SCN, modeled by means of a multi-agent based-simulation platform named SCOPE. More specifically we firstly reproduce the four-echelon serial SCN structure (i.e. 1 Retailer, 1 Wholesaler, 1 Distributor and 1 Manufacturer) adopted by Chatfield et al. (2004) under identical boundary conditions. Secondly, we generate a new divergent multi-echelon SCN model (i.e. 8 Retailer, 4 Wholesaler, 2 Distributor and 1 Manufacturer) in which each member is furnished by two downstream members. To perform the study we adopt the framework proposed by Towill et al. (2007) for studying the bullwhip effect. In this work, the authors identify three "observer's perspectives" to analyze the bullwhip effect: Variance lens, Shock lens and Filter lens. Basically, this framework suggests the typology of endogenous 
input that can be adopted in bullwhip analysis in order to study different characteristics of the SCN. More specifically we adopt two input demand patterns, i.e. the shock lens and the variance lens. The former aims at inferring on the performance of SCNs for a stationary input demand. The latter aims at inferring on the performance of SCNs for an unexpected and intense change in the end customer demand. This latter approach can be viewed as a "crash test" or a "stress test": studying the system performance under an intense and violent solicitation test to determine the resilience of a given SCN structure (Cannella and Ciancimino, 2010).

The computational results reveal that there are not significant differences in term of bullwhip effect between a divergent SCN and a serial SCN for a stationary input in customer demand. However, a violent disturbance in customer demand causes a great different between both SCNs: the divergent SCN is more sensitive to the higher forecast deviations in customer demand caused by this violent disturbance, showing higher variance of orders, taking more time to recover stability, and hence, incurring in higher costs. We can thus conclude that the divergent structure is less robust than the serial structure.

The rest of the paper is organized as follows: Section 2 presents a literature review. Section 3 describes the methodological approach. Section 4 presents the serial SCN and the divergent SCN. Section 5 presents the measurement system and the design of experiments. Section 6 presents the numerical results. Finally, Section 7 and Section 8 present findings, limitations, future directions and conclusions.

\section{Literature review}

The bullwhip effect is one of the most widely investigated phenomena in the modern day SCN management research (Nepal et al., 2012). The investigation on this phenomenon has passed through diverse phases, from empirical and ad hoc studies on bullwhip causes to mathematical approaches to infer on demand amplification solutions. Bullwhip Avoidance Phase in the term coined by Holweg and Disney (2005) to identify the current phase of the studies devoted to the demand amplification phenomenon. One distinctive feature of this phase is the focus on the efficacy of bullwhip solving approaches (Cannella and Ciancimino, 2010). To accomplish this aim, increasingly complex mathematical representations of SCNs have been developed to analyse solving approaches under several scenarios, characterised by 
reverse logistic, different forecasting techniques, stochastic lead times, collaborative systems, capacity constraints, batching, parameter configuration, pricing and so on.

Table 1 reports an overview of relevant contributions published during the Bullwhip Avoidance Phase. Articles are classified according to the focus on the parameters and factors investigated (e.g., information sharing, lead time, order policy and demand forecasting), and the typology of SCN structure (e.g. serial and non-serial).

[Table 1 near here]

All aforementioned papers have largely contributed to better understand the causes, economics consequences and remedies to bullwhip. Regardless the adopted methodological approaches, the modelled SCN structure and the metrics used to evaluate the SCN performance, the results have shown how factors such as lead time, the adoption of innovative order policy, specific forecasting techniques and different customer demand patterns can impact on the performance of SCN in terms of demand amplification. However, most of the above-reported studies, in order to quantitatively assess the performance of SCN, have exclusively adopted the classical single echelon structure or the two-stage serial SCN (Bhattacharya and Bandyopadhyay, 2011). In other studies, in order to assess the performance at different level of a multi-echelon system, it has been used the well-know four-echelon "beer-game” (Sterman, 1989) model (i.e. Retailer, Wholesaler, Distributor and Manufacturer). However, even in this case, most of those studies have adopted a classical serial SCN assumption. Essentially, most of the scientific work in SCN dynamics concerns pure retail/distribution chains or serial SCNs with few stages.

We note that there are only few studies based on the non-serial SCN modelling assumption investigating the dynamics of SCNs and demand amplification phenomenon. However, most of these papers do not report any insight on the different dynamics between a classical serial SCN structure and a divergent SCN structure. To the best of our knowledge, the work of Sodhi and Tang (2011) is one of the few papers that have reported some insights on the differences between a serial SCN and a no-serial SCN in terms of their dynamic behaviour. They report anecdotal evidence of how the bullwhip effect increases as the SCN structure becomes more complex in an arborescent SCN due to the increase in the number of echelons, or in the number of successors at each echelon. However, they do not provide any information on the magnitude of this increment. This finding stimulates the need of further structured studies on the quantification of bullwhip effect in no-serial SCNs. In our work, by adopting a 
structured framework for studying the bullwhip effect, we also clarify and extend the conclusion by Sodhi and Tang (2011). More specifically, we show how the bullwhip effect is significantly higher for a divergent $\mathrm{SCN}$ compared to a serial SCN in the case of a shock in the end customer demand. Meanwhile, the bullwhip magnitude is very similar for both SCNs where customer demand has no shock.

\section{Methodological approach}

Analytic models, like linear programming, control theory, integer programming and mixed integer programming, are among the most popular approaches for modeling SCNs. However, a SCN is a complex adaptive system that involves dynamics, stochastic, and uncertainty (Sun and Wu, 2005; Surana et al., 2005; Pathak et al., 2007; Wang et al., 2008; Chen, 2012). Unfortunately, analytical models are unable to cope with these characteristics. In addition, analytical models may prove impossible to be solved due to their complexity and nonlinearity (Long et al., 2011). Simulation has rapidly become a significant methodological approach to theory development in the literature focused on strategy, organizations and SCN management, due to its ease for modeling and its capability of handling their dynamics and stochastic behavior (Chan and Prakash, 2012; Munoz and Clements, 2008). Particularly, multi-agentbased distributed simulation turns out to be one of the most effective tools to model and analyze SCNs because there is a natural correspondence between SCN participants and agents in a simulation model (see Swaminathan et al., 1998; Julka et al., 2002; Dong et al., 2006; Chatfield et al., 2001; Govindu and Chinnam, 2010; Long et al., 2011; Chatfield et al., 2013; and Chatfield, 2013 among others). A simulation architecture that is able to both view a complex SCN and examine various causes and their effects at the same time would provide new insight to the various forces and influences in a SCN (Alony and Munoz, 2007).

SCOPE is an agent-based SCN simulator described in Cañizares and Framinan (2012) for modeling and simulating different processes taking place in SCN management, focusing in the Order Fulfilment Process and allowing an easy model of real scale SCN. Every company in the model can be set up with different policies and parameter values for the different business functions. The simulator was implemented in Java and uses Swarm (a well-known software platform for agent-based system development). It has been conceived to be opensource and help practitioners in their research. Its modular design makes easy to add new functions and behaviors to the agents and hence, it can be easily customized. 
SCOPE uses a two-layer framework for modeling the SCN. The first layer is composed of a collection of generic agents (Enterprise Agent), each one modeling a company in the SCN and interacting between themselves. The second layer includes a collection of nine different functional agents, which have been selected considering the Supply Chain Planning Matrix of Stadtler (2005). These agents are: Demand Fulfilment Agent, Demand Forecast Agent, Master Planning Agent, Production Planning Agent, MRP (Material Resource Planning) Agent, Scheduling Agent, Source Agent, Make Agent and Deliver Agent. Depending on the role played by the company, the Enterprise Agent will be composed of different combinations of these functional agents. Figure 1 shows the framework of SCOPE.

[Figure 1 near here]

Cañizares and Framinan (2012) validated SCOPE by comparing the results obtained by other authors in the literature using different methodologies. More specifically, they followed the same steps followed by Chatfield et al. (2004) to validate SISCO, a software built by the authors to simulate the storage, modeling, and generation of SCNs for Integrated Supply Chain Operations. In SISCO, the user specifies the structure and policies of a SCN using a Graphical User Interface (GUI) based application, and then saves the SCN description in the open eXtensible Markup Language (XML) based Supply Chain Modeling Language (SCML) format. SISCO automatically generates the simulation model when needed by mapping the contents of the SCML file to a library of supply-chain-oriented simulation classes. The validation of SISCO consisted of modeling a simple serial four-stage SCN and comparing its results (in terms of amplification of the standard deviation of orders) with the results obtained by two well-know authors: Chen et al. (2000), employing a statistical approach, and Dejonckheere et al. (2003), employing a control engineering approach. Table 2 shows a comparison between SISCO and SCOPE with the experiments of Chen et al. (2000). In view of these results, we can conclude that SCOPE can be considered a validated platform for the subsequent computational experience.

[Table 2 near here]

\section{Supply Chain Network employed as Testbed}

The serial SCN modeled is that of Chatfield et al. (2004), consisting of four echelons: one factory, one distributor, one wholesaler, and one retailer (Figure 2). The lower node places orders to the next upper node and this node fills these orders. The customer does not fill 
orders and the factory places orders with an outside supplier. A detailed description is provided in Chatfield et al. (2004).

A divergent SCN is characterized by a tree-like structure, where every stock point in the system receives supply from exactly one higher echelon stock point, but can supply to one or more lower echelon stock points (Hwarng et al., 2005). The divergent SCN is modeled following the next two guidelines:

1. In order to benchmark both SCNs and to isolate the main effects, the divergent SCN has to be analogous to the serial SCN of Chatfield et al. (2004). Hence, the resultant SCN should have identical values of parameters, number of stages (horizontal complexity) and, due to the divergent topology, an increasing number of nodes per stage (vertical complexity), maintaining the symmetry of the SCN.

2. Due to the prospective nature of this work, the resultant divergent SCN must have the minimum complexity. To fulfill with all requirements, each node in the SCN supplies just two nodes downstream.

The divergent SCN obtained is shown in conjunction with the serial SCN in Figure 2. The characteristics described in Chatfield et al. (2004) for the serial SCN are adapted to the divergent SCN as follows:

- Customers Demand. Each customer demand follows the same normal distribution with mean $\mu_{O_{C}}$, estimated by $\bar{D}_{O_{C}}$, and variance $\sigma_{O_{C}}^{2}$, estimated by $s_{O_{C}}^{2}$.

- Lead Time. The lead time, $L$, is stationary and independently and identically distributed with mean $\mu_{L}$ estimated by $\bar{L}$, and variance $\sigma_{L}^{2}$ estimated by $s_{L}^{2}$. The lead time of interest, or "protection period," in periodic order-up-to systems, may also include safety lead time or other constant additions to the physical lead time, depending on the inventory policy or other situational characteristics. According to Chatfield et al. (2004), all nodes in the $\operatorname{SCN}$ use the $(R, S)$ policy (where $R$ is the review period and $S$ is the order-up-to level) with $R=1$, and the time period of protection is $L+R$. The mean lead time is 4 time units for all nodes in the SCN (not including the review period, $R=1$ ), and 0 for customers. These delays are gammadistributed, with a coefficient of variation $c . v .=0.50$.

- Lead-Time Demand. Let $X_{i j}^{t}$ be the demand received by node $j$ in stage $i$ during the protection period $L+R$. Then $X_{i j}^{t}$ has mean $\mu_{X}$ that we estimate by $\bar{X}_{i j}^{t}$, and variance 
$\sigma_{X}^{2}$ that we estimate by $s_{X_{i j}^{t}}^{2}$. Denoting by $D_{i j}^{t+k}$ the demand received by node $j$ in stage $i$ at time $t+k$, we obtain $X_{i j}^{t}$ for an order placed at time $t$ by the convolution:

$$
X_{i j}^{t}=\sum_{k=0}^{L+R} D_{i j}^{t+k}
$$

- Inventory Policy and Forecasting. The order-up-to level, $S_{i j}^{t}$, is the base stock that allows the system to meet the demand during the time period $L+R$ :

$$
S_{i j}^{t}=\bar{X}_{i j}^{t}+z S_{X_{i j}^{t}}
$$

Thus, at the beginning of every period $t$, each node $j$ in stage $i$ will place an order to raise or lower the inventory position to $S_{i j}^{t}$. The term $S_{X_{i j}^{t}}$ is an estimation of the standard deviation of $X_{i j}^{t}$, and the safety factor used is $z=2.0$ (service level of $97.72 \%$ ) , according to Chatfield et al. (2004). To update the $S_{i j}^{t}$ level, a node $j$ in stage $i$ can access to the demand data from previous periods (used to forecast the expected demand at time period $t, \bar{D}_{i j}^{t}$, and its variance, $\left.s_{O_{i j}^{t}}^{2}\right)$, and to the lead time data from previous periods (used to forecast the expected lead time at time period $t, \bar{L}_{i j}^{t}$ ), and finally uses this information to generate forecasts of lead-time demand mean $\bar{X}_{i j}^{t}$ and variance $s_{X_{i j}^{t}}^{2}$, as indicated in (3) and (4), respectively:

$$
\begin{gathered}
\bar{X}_{i j}^{t}=\left(\bar{L}_{i j}^{t}+R\right) \bar{D}_{i j}^{t} \\
s_{X_{i j}^{t}}^{2}=\left(\bar{L}_{i j}^{t}+R\right) s_{O_{i j}^{t}}^{2}
\end{gathered}
$$

To estimate $\left(\bar{D}_{i j}^{t}, s_{O_{i j}^{t}}^{2}\right)$, according to Chatfield et al. (2004), each node uses a $p$-period moving averages $(M A(p))$ and a $p$-period moving variances $(M V(p))$ with $p=15$. To estimate $\left(\bar{L}_{i j}^{t}\right)$, each node uses running averages, which utilizes data available from all previous periods.

- Reverse Logistic. With the exception of the customers, all SCN nodes are allowed to return goods. Thus, replenishment order sizes may be negative. 
- Scope of Information. Each node's SCN knowledge-base is derived from the incoming demand flow coming from the downstream partners and the outgoing flow of orders being placed with the upstream partner.

- Timing of Actions. In each time period, each node (in a sequence from downstream stages to upstream stages, and randomly for nodes in the same stage) performs the following sequence of actions:

1. Update the order-up-to level $\left(S_{i j}^{t}\right)$ using the forecast calculated in the previous period.

2. Place an order to raise or lower the inventory position to the $S_{i j}^{t}$ level.

3. Receive products from the upstream node.

4. Receive new orders from the downstream nodes and satisfies demand.

5. Calculate a new forecast to be used in the next period.

[Figure 2 near here]

\section{Metrics and experiments design}

First proposed by Chen et al. (2000), the Order Rate Variance Ratio $(\Phi)$ is the most widely used indicator to detect the bullwhip effect (Cannella et al., 2013), measuring the internal process efficiency and showing the performance of each node in the SCN. It is a demandindependent measure, allowing the comparison between different SCNs. Nevertheless, measuring the internal process efficiency at the individual level (single echelon) is insufficient as it only accounts for the individual performance of each link in the chain separately (Cannella et al., 2013). Therefore, a network measure has to be used as a complementary measure of $\Phi$. The Bullwhip Slope $(B w S l)$ summarizes all the ratios obtained for each stage in a single measure, allowing a complete comparison between different SCNs at the network level (Ciancimino et al., 2012; Cannella et al., 2013). The procedure to calculate this metric is to perform a linear regression on the values of $\Phi$ using the echelon position as independent variable (equation 6). A high value of the slope means a fast propagation of the bullwhip effect through the SCN, while a low value means a smooth propagation. Since $B w S l$ is a synthesis of $\Phi$, there are similar costs associated to this metric (procurement, overtime and subcontracting) but at the network level. Below, these two metrics are summarized. 
- Order Rate Variance Ratio of a node $i\left(\Phi_{i}\right)$ : computed as the ratio of the order variance in a generic node $\left(\sigma_{O_{i}}^{2}\right.$, estimated by $\left.s_{O_{i}}^{2}\right)$ to the order variance of the end customer demand $\left(\sigma_{d}^{2}\right.$, estimated by $\left.s_{d}^{2}\right)$.

$$
\Phi_{i}=\frac{s_{O_{i}}^{2}}{s_{d}^{2}}
$$

- $B w S l$ : computed as the slope of the linear regression of the $\Phi$ curve.

$$
B w S l=\frac{K \sum_{i=1}^{K} p_{i} \Phi_{i}-\sum_{i=1}^{K} p_{i} \sum_{i=1}^{K} \Phi_{i}}{K \sum_{i=1}^{K} p_{i}^{2}-\left(\sum_{i=1}^{K} p_{i}\right)^{2}}
$$

Being $K$ the total number of echelons and $p_{i}$ the position of the $i$ th echelon.

The above mentioned metrics are easy to apply to a serial SCN, but there is one important difference when applying them to a divergent SCN, as each stage contains, in general, more than one node. In the serial SCN, the parameter required to compute the different metrics on each stage (i.e. the order variance) is taken from the only node in the stage. In the divergent $\mathrm{SCN}$, it is necessary to find an aggregate measure for the whole stage. To obtain this measure, the orders of every node $j$ in stage $i\left(O_{i j}\right)$ are considered at the same time and added, resulting in an aggregate order pattern for the stage $i: A O_{i}=\sum_{j=1}^{n_{i}} O_{i j}$, being $n_{i}$ the number of nodes in the stage $i$. Following the same procedure, the aggregate end customer demand pattern can be obtained as $A d=\sum_{j=1}^{n_{C}} O_{C j}$, being $n_{C}$ the number of customers. Then, the aggregate variance of each stage $\left(\sigma_{A O_{i}}^{2}, \sigma_{A d}^{2}\right)$ can be estimated $\left(s_{A O_{i}}^{2}, s_{A d}^{2}\right)$, and $\Phi_{i}$ is:

$$
\Phi_{i}=\frac{s_{A O_{i}}^{2}}{s_{A d}^{2}}
$$

In view of the fact that all the customer demands are assumed to be independent and that each node places orders independently, the aggregate variance in each stage $i$ is the sum of the variances of orders of each node $j$ in the stage $i\left(\sigma_{O_{i j}}^{2}, \sigma_{O_{C j}}^{2}\right)$, estimated by $\left(s_{O_{i j}}^{2}, s_{O_{C j}}^{2}\right)$, and thus, the calculation of $\Phi_{i}$ :

$$
\Phi_{i}=\frac{\sum_{j=1}^{n_{i}} s_{O_{i j}}^{2}}{\sum_{j=1}^{n_{C}} s_{O_{C j}}^{2}}
$$


Chatfield et al. (2004) analyze the impact of stochastic lead times, information quality and information sharing on the performance of SCNs, carrying out a factorial experiment utilizing these three indicators. For the comparison between the serial and the divergent SCNs, we have taken the following values of these factors from their factorial experiment: lead time coefficient of variation c.v. $=0.50$; no information sharing; quality of information utilized for updating the $S$ level shown in equations (3) and (4) (named IQL1 by Chatfield et al., 2004). These factors remain fixed in our experiments.

For the bullwhip analysis, we adopt the framework proposed by Towill et al. (2007) (see Section 1). Attending to the variance lens perspective, the demand pattern is the same as in Chatfield et al. (2004), i.e. demands follows a $N\left(50,20^{2}\right)$ distribution. Attending to the shock lens perspective, we use a $N\left(50,20^{2}\right)$ distribution, which suffer an average increment of $100 \%$ in the middle of the simulation time (not considering the warm-up period, see below), turning into a $N\left(100,20^{2}\right)$. These demand patterns are applied to the only customer in the serial SCN, and to every customer in the divergent SCN.

We design two sets of experiments: the stationary response set and the dynamic response set. In the stationary response set, in order to compare the performance of the serial and the divergent SCNs under both lenses, a global measure of $\Phi$ and $B w S l$ are obtained for both demand patterns. In the dynamic set, the temporal evolution of $\Phi$ is obtained under the shock lens in order to analyze the impulse response of both SCNs in detail.

In the first set of experiments, a simulation experiment has been carried out for each SCN and for each demand pattern. Following the simulation procedure indicated in Chatfield et al. (2004), each experiment consists in 30 replications of 700 periods, with the first 200 periods of each replication removed as a warm-up used to set up the system. The results obtained from the replications are averaged for each experiment. To be able to compare the experiments under both lenses, metrics are calculated in the same simulation period, after the impulse time $(t=450)$. The first set of experiments is summarized in Table 3.

[Table 3 near here]

In the second set of experiments, in order to obtain the temporal response, each $\mathrm{SCN}$ is evaluated in different simulation periods. In the first observation, named $T 0$, SCNs are simulated until the simulation time is just before the demand impulse occurs, obtaining the initial $\Phi$. Then, $\Phi$ is measured in a sequence of experiments where the simulation time starts at the demand impulse instant and the simulation time is increasing in intervals of 25 or 50 
periods until the end of the original simulation time is reached $(t=700)$, resulting in the experiments T1-T6. As for the first set, each experiment consists in 30 replicates, and the results obtained are averaged. This set of experiments is summarized in Table 4.

[Table 4 near here]

\section{Numerical Results}

\subsection{Stationary response set}

Under the variance lens, results obtained for $\Phi$ are very similar for both SCNs (see Figure 3), being slightly higher for the divergent $\mathrm{SCN}$ at the upper stages. However, under the shock lens there is an important difference between both SCNs, as $\Phi$ is considerably higher for the divergent SCN (see Figure 4). The average results for $\Phi$ and $B w S l$, as well as the differences between both SCNs $\left(\Delta(\%)=\frac{\Phi_{\text {Divergent }}-\Phi_{\text {Serial }}}{\Phi_{\text {Serial }}} * 100 \%\right)$ are shown in Table 5, together with the corresponding $99 \%$-confidence intervals.

Under the variance lens, it can be seen that the values of the measures are not statistically different, which indicates a rather similar performance for both SCNS. At the lower stages, the increase of $\Phi$ is below $1 \%$, while at the upper stages the differences are slightly higher ( $\Phi$ is $5.39 \%$ higher for the divergent $\mathrm{SCN}$ at the distributor stage and $6.08 \%$ at the factory stage). $B w S l$ helps to easily compare both SCNs. The propagation of the bullwhip effect is very similar for both SCNs, being slightly higher $(6.20 \%)$ for the divergent SCN.

[Figure 3 near here]

[Figure 4 near here]

Under the shock lens, the $\Phi$ curve is clearly stepped for the divergent SCN, with the minimum increase at the retailer stage $(1.32 \%$ over the serial $\mathrm{SCN})$ and the maximum increase at the factory stage $(95.86 \%$ over the serial SCN). The bad performance of the divergent SCN in this case is well summarized by the value of $B w S l$, being $94.62 \%$ higher than in the serial SCN. Note that the differences in the indicators for both SCNs are statistically different, thus confirming that the divergent SCN performs worse than the serial $\mathrm{SCN}$ in this scenario.

[Table 5 near here]

\subsection{Dynamic response set}

Figure 5 shows the evolution of $\Phi$ over time for each stage after the demand impulse (rhomboids dots for the serial $\mathrm{SCN}$ and square dots for the divergent $\mathrm{SCN}$ ). The differences 
for $\Phi$ observed between both SCNs in Figure 5 are plotted in Figure 6, showing the temporal evolution of $\Delta(\%)$ for each stage. Under an unexpected impulse in demand average:

- Both SCNs react by: 1) immediately incrementing their order variances in all stages, and 2) decreasing their order variances over time.

- The highest increase in $\Phi$ takes place just after the demand impulse (T1). The difference between both SCNs is maximal at this point, being higher as we move upstream (see Figure 6).

- The shock recovery is similar for both SCNs at the lower stages (retailers and wholesalers), whereas $\Delta(\%)$ is near to zero after $T 3$ (see Figure 6). However, at the upper stages (distributors and factory), shock recovery is slower for the divergent SCN, obtaining high values of $\Delta(\%)$ until the end of the simulation time (T6).

[Figure 5 near here]

[Figure 6 near here]

In Figure 7, the order pattern at the factory stage is plotted against the customer order pattern for both SCNs under the shock lens. It is easy to see the high overreaction of the divergent SCN when the demand impulse occurs.

[Figure 7 near here]

Finally, a sensitivity analysis has been performed by systematically increasing the level of end customer standard deviation in the shock lens part of the simulation. The results show that as the impulse in customer demand variability increases, standard deviation of the orders placed in the lower echelons does not increase at the same rate. For example, $47.49 \%$ increase in customer demand standard deviation in the shock lens, resulted a $25.96 \%$ increase in the standard deviation of the factory orders. In other words, the increase in the shock was transmitted in lower proportions towards the upstream levels of the supply chain.

\section{Findings and managerial implications}

The results obtained in the previous section give new insights on the bullwhip effect research topic, considering two different lenses for the comparison of two different SCN structures. Under the variance lens, the following comments can be done:

- The bullwhip effect found in the serial and the divergent SCNs are very similar. When the demand is predictable and the nodes can adequately adjust their inventory levels to 
fulfill the demand with a high customer service level, both SCNs are quasiequivalents. A node at the stage $i$ of the divergent $\mathrm{SCN}$ causes the same amplification of orders that a node in the same stage $i$ of the serial SCN, because they have the same order-up-to and forecast policies. The orders received by each node are proportional to the end customer demand, and hence, to the amplification of orders caused by them. As the variance of orders in each stage is rated to the end customer demand variance, each stage produces similar values of $\Phi$ for both SCNs.

- The small increase observed in $\Phi$ for the divergent SCN in Figure 3 is caused by eventual excess of stock or by eventual stock-outs. Due to the uncertainties in the end customer demand and lead times, sometimes either the demand received may be different than the demand forecasted in the previous period, or the orders arrive earlier or later than expected, causing this phenomenon. In these cases, where the inventory level is far from the desired order-up-to level, a node reacts by ordering a big quantity of products (a positive order in case of stock-out and a negative order in case of excess of inventory). These exceptionally high orders are amplified upstream, increasing the variance ratio mainly in the upper stages. In view of the fact that for each node there is a certain probability that this phenomenon occurs, and that the divergent $\mathrm{SCN}$ has a higher number of nodes in each stage (higher vertical complexity), it happens more frequently in the divergent $\mathrm{SCN}$, causing the little increment in the values of $\Phi$ at the upper stages (distributor and factory). As a summary, we can conclude that the divergent SCN has almost the same performance in terms of bullwhip effect than the serial SCN when the end customer demand does not suffer important changes.

Using the shock lens, the following comments can be done:

- Under the shock lens both SCNs are stress tested. The end customer demand impulse causes a massive stock-out situation at the retailer stage, which is then propagated and amplified along the SCN, causing stock-outs in all the stages of the SCNs. While the factory in the serial SCN has to manage the instability caused by the stock-out of one retailer, the same factory in the divergent $\mathrm{SCN}$ has to manage it with the stock-outs of eight retailers. The disproportional orders of the factory and distributors in the divergent SCN can be observed in Figure 7, and are the cause of: the excess of variance observed in Figure 4, the high peaks of variances, and the slow recovery observed in Figure 5. 
- The divergent SCN has a bad performance as compared to the serial SCN under important unpredicted changes in demand tendencies. We can thus conclude that divergent SCNs are less robust than serial SCNs.

It is worth mentioning the relevance of the framework for the analysis of the bullwhip effect proposed by Towill et al. (2007). The authors stated that "the detection of bullwhip effect depends on which lens is used", and they proposed three different lenses for bullwhip analysis (variance, shock and filter lens). Our experiments have shown different behaviors depending on the lens used: while for the classical variance lens analysis (stationary stochastic demand input) the bullwhip effect is similar for both SCNs, the shock lens analysis (step demand input) reveals that the divergent SCN performs worse than the serial SCN.

With respect to the managerial implications of the study, to face up with the less robustness of divergent SCNs, managers may find useful to consider the following:

- Under a shock in end customer demand, the bullwhip effect increases when the SCN structure becomes more complex as the number of echelons increases, or as the number of successors at each echelon increases. Thus, to mitigate this incremental bullwhip effect, a firm could consider simplifying the SCN structure by reducing the number of echelons or by reducing the number of successors (Sodhi and Tang, 2011). This is particularly important for SCNs characterized by high variations in the end customer demand. On the contrary, traditional arborescent SCNs operaing in markets characterized by a stable consumer demand are less prone to the detrimental consequences of the demand amplification phenomenon.

- An adequate forecast method adjusted to the end customer demand would prevent the firm from eventual excess of stock or from stock-outs. Therefore, it is important to make an effort to implement techniques in order to better understand the end customer demand tendencies (i.e. surveys) and to anticipate important changes.

- The implementation of well-known techniques for reducing the bullwhip effect (i.e. information sharing) is highly desirable. These techniques may help managers to have a better control of the bullwhip effect in case of important changes in the end customer demand that cannot be anticipated by the above techniques. However, it has yet to be proved how these techniques (usually tested in serial SCNs) perform in non-serial SCNs. 


\section{Conclusions}

The literature review has revealed a lack of research on the bullwhip effect topic when the structure of the SCN is different than a serial SCN. However, real SCNs rarely adopt a traditional serial structure, often following a more complex topology. The present work is a first attempt to cover this research gap by analyzing the bullwhip effect in a divergent SCN and by comparing its performance with those of a serial SCN already analyzed in the literature by several authors. This analysis has been carried out using the variance lens and the shock lens proposed by Towill et al., (2007). The bullwhip effect has been observed both from a static and a dynamic perspective, being measured at the node level by the Order Rate Variance Ratio (which has been adapted to the divergent SCN), and at the network level by the Bullwhip Slope.

The main result obtained show that divergent SCNs are more sensitive to unexpected violent changes in demand signal than serial SCNs. Two situations have been considered:

- Variance lens, i.e. stationary demand signal. In this case the performance of both SCNs is very similar, being just a little worse for divergent SCNs.

- Shock lens, i.e. demand signal suffers an unexpected violent change. In this case the performance of the divergent SCN is much worse than that of the serial SCN, showing higher variance of orders and taking more time for recovery, incurring in higher costs.

Bhattacharya and Bandyopadhyay (2011) indicated that there are operational and behavioral causes of the bullwhip effect, and that the root of all the causes is the lack of coordination among the SCN members. Our paper shows that there are also structural factors that amplify the bullwhip effect caused by those operational and behavioral factors.

Our study is of an exploratory nature since this topic that has not been previously addressed. Therefore we have tried to not add excessive complexity that may obscure the interpretation of the results. This comes at the price of a number of limitations that have been identified and that constitute future research lines. Some of these are:

- The present work is limited by fixed operational factors (order-up-to policy, forecasting, etc.) and by the SCN structure itself. As underlined by Dejonckheere et al. (2004), more or less bullwhip could be obtained by selecting other vectors of parameters. A deeper analysis must be done to better understand this type of SCNs, 
considering different operational factors and structural factors (horizontal and vertical complexity).

- The less robust structure of the divergent SCN might be compensated by a good information system, in order to share end customer demand (information sharing) and current inventory levels (synchronized supply, see Cannella and Ciancimino, 2010; Ciancimino et al., 2012), allowing a faster and proportional response to violent changes in the end customer demand. Such information system can be adapted to divergent SCNs and its efficiency tested.

- It has been shown that, in addition to the number of stages, other structural factors may influence the bullwhip effect. An identification of these factors and a quantification of their effects could be done.

\section{Acknowledgments}

We wish to thank the anonymous referees for insightful comments on earlier versions of the paper. This research was funded by a grant from the Junta de Andalucía (Spain), grant P08TEP-03630, and the Spanish Ministry of Science and Innovation, under the project "SCORE" with reference DPI2010-15573/DPI.

\section{References}

Adenso-Díaz, B., Moreno, P., Gutiérrez, E., Lozano, S. 2012. An analysis of the main factors affecting bullwhip in reverse supply chains. International Journal of Production Economics, 135 (2), 917-928.

Aggelogiannaki, E., Doganis, P., Sarimveis, H. 2008. An adaptive model predictive control configuration for production-inventory systems. International Journal of Production Economics, 114 (1), 165-178.

Agrawal, S., Sengupta, R.N., Shanker, K. 2009. Impact of information sharing and lead time on bullwhip effect and on-hand inventory. European Journal of Operational Research, 192 (2), 576-593.

Ali, M.M., Boylan, J.E. 2011. On the effect of non-optimal forecasting methods on supply chain downstream demand. IMA Journal Management Mathematics, 23 (1), 81-98.

Alony, I., Munoz, A. 2007. The Bullwhip effect in complex supply chains. ISCIT 2007 - 2007 International Symposium on Communications and Information Technologies Proceedings, art. no. 4392227, 1355-1360. 
Barlas, Y., Gunduz, B. 2011. Demand forecasting and sharing strategies to reduce fluctuations and the bullwhip effect in supply chains. Journal of the Operational Research Society, 62 (3), 458-473.

Beamon, B.M., Chen, V.C.P. 2001. Performance analysis of conjoined supply chains. International Journal of Production Research, 39 (14), 3195-3218.

Bhattacharya, R., Bandyopadhyay, S. 2011. A review of the causes of bullwhip effect in a supply chain. International Journal of Advanced Manufacturing Technology, 54 (9-12), 1245-1261.

Bottani, E., Montanari, R., Volpi, A. 2010. The impact of RFID and EPC network on the bullwhip effect in the Italian FMCG supply chain. International Journal of Production Economics, 124 (2), 426-432.

Butner, K. (2010). The smarter supply chain of the future. Strategy and Leadership, 38 (1), 22-31.

Byrne, P.J., Heavey, C. 2006. The impact of information sharing and forecasting in capacitated industrial supply chains: A case study. International Journal of Production Economics, 103 (1), 420-437.

Cachon, G., Fisher, M. 2000. Supply chain inventory management and the value of shared information. Management Science, 46 (8), 1032-1048.

Caloiero, G., Strozzi, F., Zaldívar Comenges, J.M. 2008. A supply chain as a series of filters or amplifiers of the bullwhip effect. International Journal of Production Economics, 114 (2), 631-645.

Cannella, S., Barbosa-Povoa, A.P., Framinan J.M., Relvas S. 2013. Metrics for bullwhip effect analysis. Journal of the Operational Research Society, 64 (1), 1-16.

Cannella, S., Ciancimino, E. 2010. On the bullwhip avoidance phase: supply chain collaboration and order smoothing. International Journal of Production Research, 48 (22), 6739-6776.

Cannella, S., Ciancimino, E., Framinan, J.M. 2011. Inventory policies and information sharing in multi-echelon supply chains. Production Planning \& Control, 22 (7), 649-659.

Cañizares, R.D., Framinan, J.M. 2012. Development of a multi-agent platform for supply chain-wide order fulfilment. ICAART 2012 - Proceedings of the 4th International Conference on Agents and Artificial Intelligence, 2, 203-208.

Chaharsooghi, S.K., Heydari, J. 2010. LT variance or LT mean reduction in supply chain management: Which one has a higher impact on SC performance? International Journal of Production Economics, 124 (2), 475-481.

Chan, F.T.S, Prakash, A. 2012. Inventory management in a lateral collaborative manufacturing supply chain: a simulation study. International Journal of Production Research, 50 (16), 4670-4685.

Chandra, C., Grabis, J. 2005. Application of multi-steps forecasting for restraining the bullwhip effect and improving inventory performance under autoregressive demand. European Journal of Operational Research, 166 (2), 337-350. 
Chatfield, D.C. 2013. Underestimating the bullwhip effect: a simulation study of the decomposability assumption. International Journal of Production Research, 51 (1), 230254.

Chatfield D.C., Pritchard A.M. 2013. Returns and the bullwhip effect. Transportation Research Part E: Logistics and Transportation Review, 49 (1), 159-175.

Chatfield, D.C., Hayya, J.C., Cook, D.P. 2013. Stockout propagation and amplification in supply chain inventory systems. International Journal of Production Research, 51 (5), 1491-1507.

Chatfield, D.C., Kim, J.G., Harrison, T.P., Hayya, J.C. 2004. The bullwhip effect - Impact of stochastic lead time, information quality, and information sharing: A simulation study. Production and Operations Management, 13 (4), 340-353.

Chatfield, D., Harrison, T., Hayya, J. 2001. SISCO: A supply chain simulation tool utilizing Silk $^{\mathrm{TM}}$ and XML. Winter Simulation Conference Proceedings, 1, 614-622.

Chen, H.-H. 2012. Simulating analysis of complex supply chain networks invulnerability. Lecture Notes in Electrical Engineering 154 LNEE, 1229-1235.

Chen, X., Hao, G., Li, X., Yiu, K.F.C. 2012. The impact of demand variability and transshipment on vendor's distribution policies under vendor managed inventory strategy. International Journal of Production Economics, 139 (1), 42-48.

Chen, L., Lee, H.L. 2009. Information Sharing and Order Variability Control under a Generalized Demand Model. Management Science, 55(5), 781-798.

Chen, Y.F., Disney, S.M. 2007. The myopic Order-Up-To policy with a proportional feedback controller. International Journal of Production Research, 45 (2), 351-368.

Chen, F., Drezner, Z., Ryan, J., Simchi-Levi, D. 2000. Quantifying the bullwhip effect in a simple supply chain: the impact of forecasting, lead times, and information. Management Science, 46 (3), 436-443.

Cho, D.W., Lee, Y.H. 2013. The value of information sharing in a supply chain with a seasonal demand process. Computers and Industrial Engineering, 65 (1), 97-108.

Christopher, M., Holweg, M. 2011. "Supply Chain 2.0": Managing supply chains in the era of turbulence. International Journal of Physical Distribution and Logistics Management, 41 (1), 63-82.

Ciancimino E., Cannella S., Bruccoleri M., Framinan, J.M. 2012. On the bullwhip avoidance phase: the Synchronised Supply. European Journal of Operational Research, 22 (1), 4963.

Dass, M., Fox, G.L. 2011. A holistic network model for supply chain analysis. International Journal of Production Economics, 131 (2), 587-594.

Dejonckheere, J., Disney, S., Lambrecht, M., Towill, D. 2003. The impact of information enrichment on the Bullwhip effect in supply chains: A control engineering perspective. European Journal of Operational Research, 153 (3), 727-750.

Dejonckheere, J., Disney, S.M., Lambrecht, M.R., Towill, D.R. 2002. Transfer function analysis of forecasting induced bullwhip in supply chains. International Journal of Production Economics, 78 (2), 133-144. 
Dejonckheere, J., Disney, S.M., Lambrecht, M.R., Towill, D.R. 2003. Measuring and avoiding the bullwhip effect: A control theoretic approach. European Journal of Operational Research, 147 (3), 567-590.

Disney, S.M., Grubbström, R.W. 2004. Economic consequences of a production and inventory control policy. International Journal of Production Research, 42 (17), 34193431 .

Disney, S.M., Towill, D.R. 2003a. On the bullwhip and inventory variance produced by an ordering policy. Omega, the International Journal of Management Science, 31 (3), 157167.

Disney, S.M., Towill, D.R. 2003b. The effect of vendor managed inventory (VMI) dynamics on the Bullwhip Effect in supply chains. International Journal of Production Economics, 85 (2), 199-215.

Disney, S.M., Farasyn, I., Lambrecht, M., Towill, D.R., de Velde, W.V. 2006. Taming the bullwhip effect whilst watching customer service in a single supply chain echelon. European Journal of Operational Research, 173 (1), 151-172.

Disney, S.M., Lambrecht, M., Towill, D.R., Van de Velde, W. 2008. The value of coordination in a two-echelon supply chain. IIE Transaction, 40 (3), 341-355.

Disney, S.M., Naim, M.M., Potter, A. 2004a. Assessing the impact of e-business on supply chain dynamics. International Journal of Production Economics, 89 (2), 109-118.

Disney, S.M., Towill, D.R., Van De Velde, W. 2004b. Variance amplification and the golden ratio in production and inventory control. International Journal of Production Economics, 90 (3), 295-309.

Dooley, K.J., Yan T., Mohan S., Gopalakrishnan, M. 2010. Inventory management and the bullwhip effect during the 2007-2009 recession: Evidence from the manufacturing sector. Journal of Supply Chain Management, 46 (1), 12-18.

Dong, S.-H., Xi, B., Tian, L.-N., Huang, Q.-G., Chen, H.-X. 2006. An agent-based architecture for supply chain management. Proceedings of the 2006 International Conference on Machine Learning and Cybernetics, art. no. 4028046, 137-141.

Dvorak, P. 2009. “'Clarity Is Missing Link in Supply Chain,'” Wall Street Journal, May18, 2009.

Ganeshan, Ram. 1999. Managing supply chain inventories: A multiple retailer, one warehouse, multiple supplier model. International Journal of Production Economics, 59 (1), pp. 341-354.

Garcia Salcedo, C.A., Ibeas Hernandez, A., Vilanova, R., Herrera Cuartas, J. 2013. Inventory control of supply chains: Mitigating the bullwhip effect by centralized and decentralized Internal Model Control approaches. European Journal of Operational Research, 224 (2), 262-272.

Gonçalves, P., Hines, J., Sterman, J. 2005. The impact of endogenous demand on push-pull production system. System Dynamics Review, 21 (3), 187-216.

Govindu, R., Chinnam, R.B. 2010. A software agent-component based framework for multiagent supply chain modeling and simulation. International Journal of Modeling and Simulation, 30 (2), 155-171. 
Holweg, M., Disney, S.M. 2005. The Evolving Frontiers of the Bullwhip Problem. In EUROMA Conference Proceedings. Budapest, Hungary, 19-22 June, 707-716.

Hosoda, T., Disney, S. M. 2006a. On variance amplification in a three-echelon supply chain with minimum mean square error forecasting. Omega, the International Journal of Management Science, 34 (4), 344-358.

Hosoda, T., Disney, S. M. 2006b. The governing dynamics of supply chains: The impact of altruistic behaviour. Automatica, 42 (8), 1301-1309.

Hosoda, T., Naim, M.M., Disney, S. M. Potter, A. 2008. Is there a benefit to sharing market sales information? Linking theory and practice. Computers and Industrial Engineering, 54 (2), 315-326.

Hung, S.-J. 2011. Activity-based divergent supply chain planning for competitive advantage in the risky global environment: A DEMATEL-ANP fuzzy goal programming approach. Expert Systems with Applications, 38 (8), 9053-9062.

Hussain, M., Drake, P.R. 2011. Analysis of the bullwhip effect with order batching in multiechelon supply chains. International Journal of Physical Distribution and Logistics Management, 4 (8), 797-814.

Hussain, M., Shome, A., Lee, D.M. 2012. Impact of forecasting methods on variance ratio in order-up-to level policy. International Journal of Advanced Manufacturing Technology, 59 (1-4), 413-420.

Hwarng, H.B., Chong, C.S.P., Xie, N., Burgess, T.F. 2005. Modelling a complex supply chain: Understanding the effect of simplified assumptions. International Journal of Production Research, 43 (13), 2829-2872.

Ingalls, R.G., Foote, B.L., Krishnamoorthy, A. 2005. Reducing the bullwhip effect in supply chains with control-based forecasting. International Journal of Simulation and Process Modelling, 1/2, 90-110.

Jakšič, M., Rusjan, B. 2008. The effect of replenishment policies on the bullwhip effect: a transfer function approach. European Journal of Operational Research, 184 (3), 946-961.

Julka, N., Srinivasan, R., Karimi, I. 2002. Agent-based supply chain management - 1: Framework. Computers and Chemical Engineering, 26 (12), 1755-1769.

Kelepouris, T., Miliotis, P., Pramatari K. 2008. The impact of replenishment parameters and information sharing on the Bullwhip effect: a computational study. Computers and Operations Research, 35 (11), 3657-3670.

Kim, I., Springer, M. 2008. Measuring endogenous supply chain volatility: Beyond the bullwhip effect. European Journal of Operational Research, 189 (1), 172-193.

Kim, J.G., Chatfield, D., Harrison, T.P., Hayya, J.C. 2006. Quantifying the bullwhip effect in a supply chain with stochastic lead time. European Journal of Operational Research, 173 (2), 617-636.

Kristianto, Y., Helo, P., Jiao, J.R., Sandhu, M. 2012. Adaptive fuzzy vendor managed inventory control for mitigating the Bullwhip effect in supply chains. European Journal of Operational Research, 216 (2), 346-355. 
Lalwani, C.S., Disney, S.M., Towill, D.R. 2006. Controllable, observable and stable state space representations of a generalized order-up-to policy. International Journal of Production Economics, 101 (1), 172-184.

Lee, H. L., Padmanabhan, V., Whang, S. 1997. Information distortion in a Supply Chain: The Bullwhip effect. Management Science, 43 (4), 546-558.

Lee, H.L. 2010. Taming the bullwhip. Journal of Supply Chain Management, 46 (1), 7-7.

Li, C., Liu, S. 2013. A robust optimization approach to reduce the bullwhip effect of supply chains with vendor order placement lead time delays in an uncertain environment. Applied Mathematical Modelling, 37 (3), 707-718.

Li, Z., Duan, N. 2009. Exploring the bullwhip effect through supply chain simulation software. PACIIA 2009 - 2009 2nd Asia-Pacific Conference on Computational Intelligence and Industrial Applications, 1, art. no. 5406476, 139-142.

Long, Q., Lin, J., Sun, Z. 2011. Modeling and distributed simulation of supply chain with a multi-agent platform. International Journal of Advanced Manufacturing Technology, 55 (912), 1241-1252.

Ma, Y., Wang, N., Che, A., Huang, Y., Xu, J. 2013. The bullwhip effect on product orders and inventory: a perspective of demand forecasting techniques. International Journal of Production Research, 51 (1), 281-302.

Machuca, J.A.D., Barajas, R.P. 2004. The impact of electronic data interchange on reducing bullwhip effect and supply chain inventory costs. Transportation Research Part E: Logistics and Transportation Review, 40 (30), 209-228.

Moser, R., Kern, D., Wohlfarth, S., Hartmann, E. 2011. Supply network configuration benchmarking: Framework development and application in the Indian automotive industry. Benchmarking, 18 (6), 783-801.

Nepal, B., Murat, A., Babu Chinnam, R. 2012. The bullwhip effect in capacitated supply chains with consideration for product life-cycle aspects. International Journal of Production Economics, 136 (2), 318-33.

Ouyang, Y., Daganzo, C. 2006. Characterization of the bullwhip effect in linear, timeinvariant supply chains: Some formulae and tests. Management Science, 52, 1544-1556.

Ouyang, Y., Li, X. 2010. The bullwhip effect in supply chain networks. European Journal of Operational Research, 201 (3), 799-810.

Pathak, S.D., Day, J.M., Nair, A., Sawaya, W.J., Kristal, M.M. 2007. Complexity and adaptivity in supply networks: Building supply network theory using a complex adaptive systems perspective. Decision Sciences, 38 (4), 547-580.

Riddalls, C.E., Bennett, S., Tipi, N.S. 2000. Modelling the dynamics of supply chains. International Journal of Systems Science, 31 (8), 969-976.

Sari, K. 2010. Exploring the impacts of radio frequency identification (RFID) technology on supply chain performance. European Journal of Operational Research, 207 (1), 174-183.

Shang, J.S., Li, S., Tadikamalla, P. 2004. Operational design of a supply chain system using the Taguchi method, response surface methodology, simulation, and optimization. International Journal of Production Research, 42 (18), 3823-3849. 
Stadtler, H. 2005. Supply chain management and advanced planning - Basics, overview and challenges. European Journal of Operational Research, 163 (3), 575-588.

Stank, T.P., Dittmann, J.P., Autry, C.W. 2011. The new supply chain agenda: A synopsis and directions for future research. International Journal of Physical Distribution and Logistics Management, 41 (10), 940-955.

Sterman, J. 1989. Modeling managerial behavior: misperceptions of feedback in a dynamic decision making experiment. Management Science, 35(3), 321-339.

Strozzi, F., Noè, C., Zaldívar, J.M. 2008. The control of local stability and of the bullwhip effect in a supply chain. International Journal of Production Economics, 114, 631-645.

Su, Y., Geunes, J. 2012. Price promotions, operations cost, and profit in a two-stage supply chain. Omega, the International Journal of Management Science, 40 (6), 891-905.

Sun, H., Wu, J. 2005. Scale-free characteristics of supply chain distribution systems. Modern Physics Letters B, 19 (17), 841-848.

Surana, A., Kumara, S., Greaves, M., Raghavan, U.N. 2005. Supply-chain networks: A complex adaptive systems perspective. International Journal of Production Research, 43 (20), 4235-4265.

Swaminathan, J.M., Smith, S.F., Sadeh, N.M. 1998. Modeling supply chain dynamics: A multiagent approach. Decision Sciences, 29 (3), 607-631.

Towill, D.R., Zhou, L., Disney, S.M. 2007. Reducing the bullwhip effect: Looking through the appropriate lens. International Journal of Production Economics, 108 (1-2), 444-453.

Trapero, J.R., Kourentzes, N., Fildes, R. 2012. Impact of information exchange on supplier forecasting performance. Omega, the International Journal of Management Science, 40 (6), 738-747.

Villegas, F.A., Smith, N.R. 2006. Supply chain dynamics: Analysis of inventory vs. order oscillations trade-off. International Journal of Production Research, 44 (6), 1037-1054.

Wang, K., Zeng, Z., Sun, D. 2008. Structure analysis of supply chain networks based on complex network theory. 4th international conference on semantics, knowledge and grid, 3-5 December, Beijing, China.

Warburton, R.D.H. 2004. An analytical investigation of the Bullwhip Effect. Production and Operations Management, 13 (2), 150-160.

Wright, D., Yuan, X. 2008. Mitigating the bullwhip effect by ordering policies and forecasting methods. International Journal of Production Economics, 113 (2), 587-597.

Xuan, Q., Du, F., Li, Y., Wu, T.-J. 2011. A framework to model the topological structure of supply networks. IEEE Transactions on Automation Science and Engineering, 8 (2), 442446.

Yang, T., Wen, Y.-F., Wang, F.-F. 2011. Evaluation of robustness of supply chain information-sharing strategies using a hybrid Taguchi and multiple criteria decision-making method. International Journal of Production Economics, 134 (2), 458-466.

Yuan, X., Shen, L., Ashayeri, J. 2010. Dynamic Simulation Assessment of Collaboration Strategies to Manage Demand Gap in High-tech Product Diffusion. International Journal of Computer Integrated Manufacturing, 25 (6), 647-657. 
Zhang, X., 2004. The impact of forecasting methods on the bullwhip effect. International Journal of Production Economics, 88 (1), 15-27.

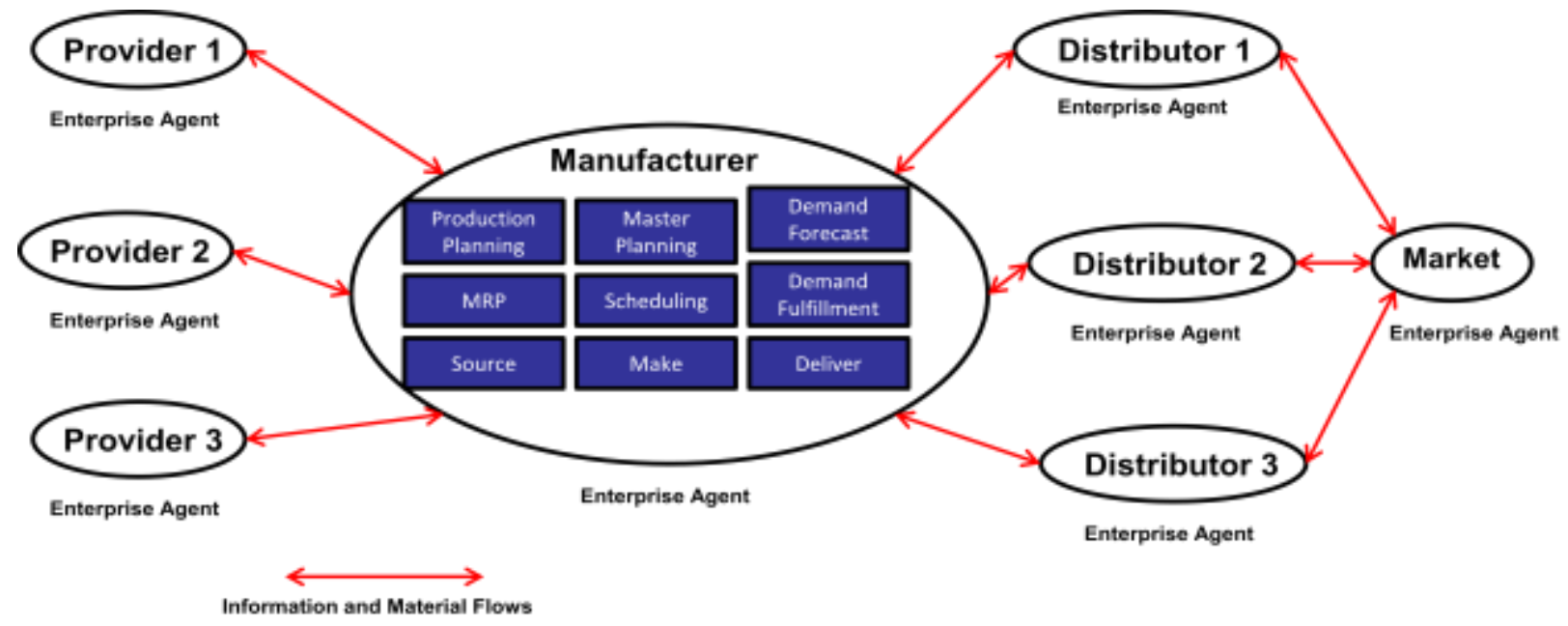

Figure 1: Multi-Agent Framework of SCOPE.

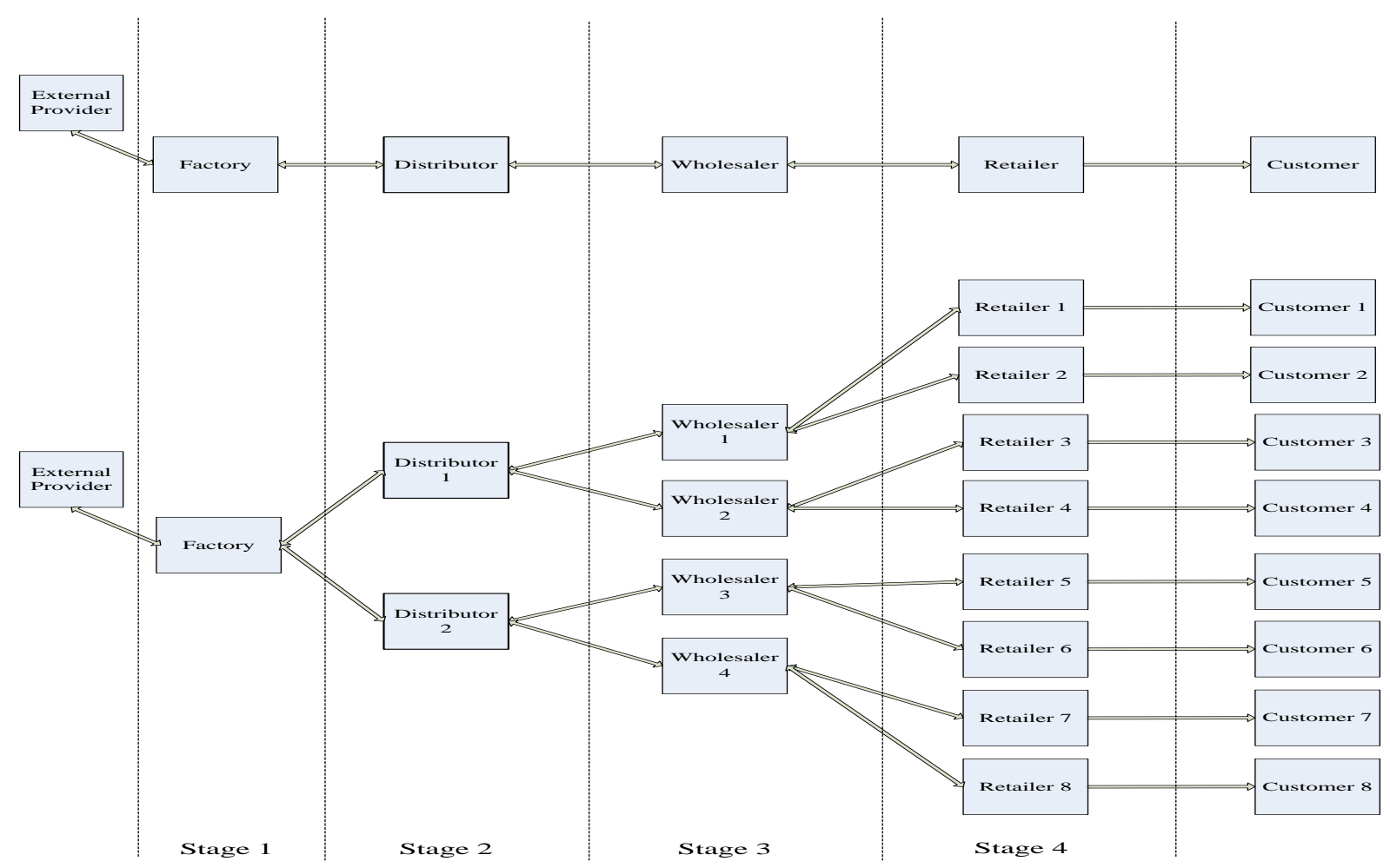

Figure 2. Serial vs Divergent SCNs. 


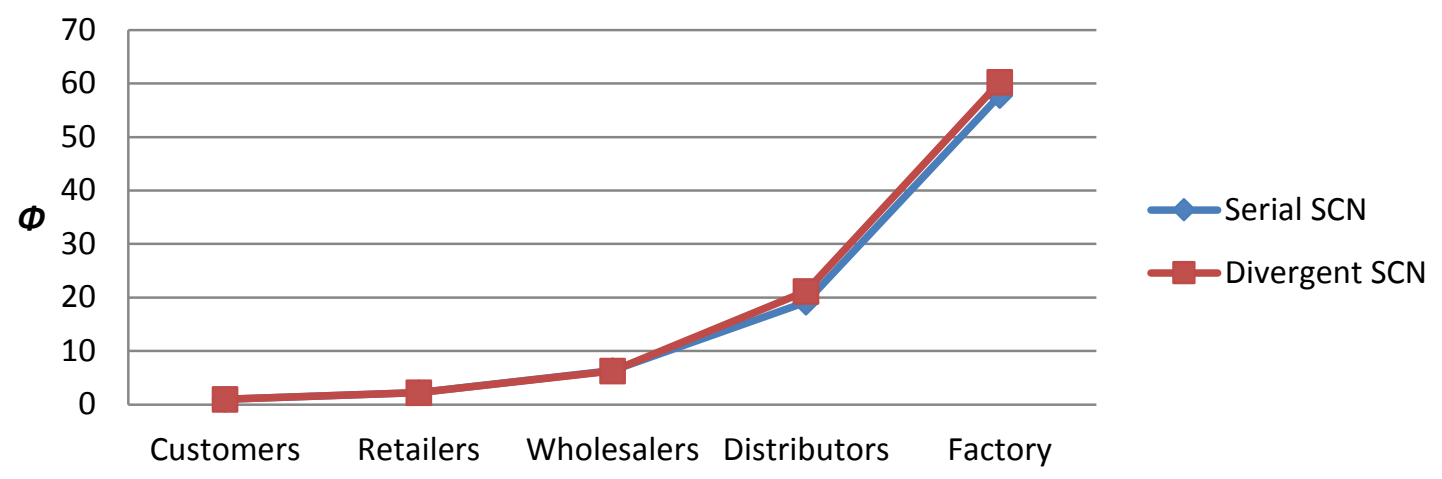

Figure 3. $\Phi$ under the Variance Lens.

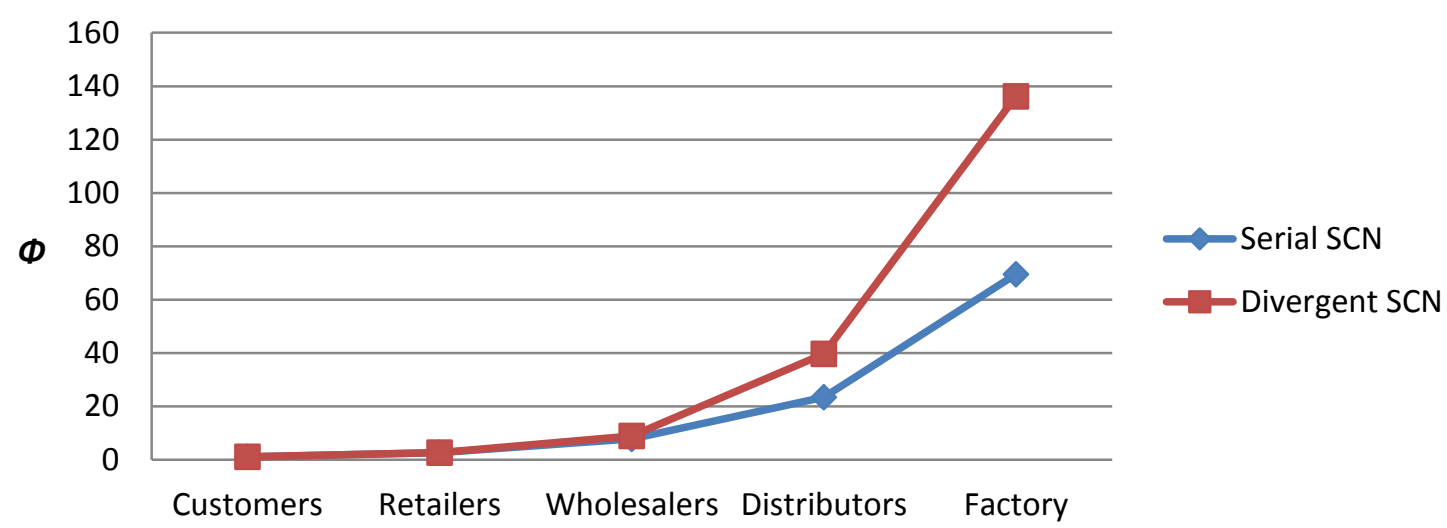

Figure 4. $\Phi$ under the Shock Lens. 

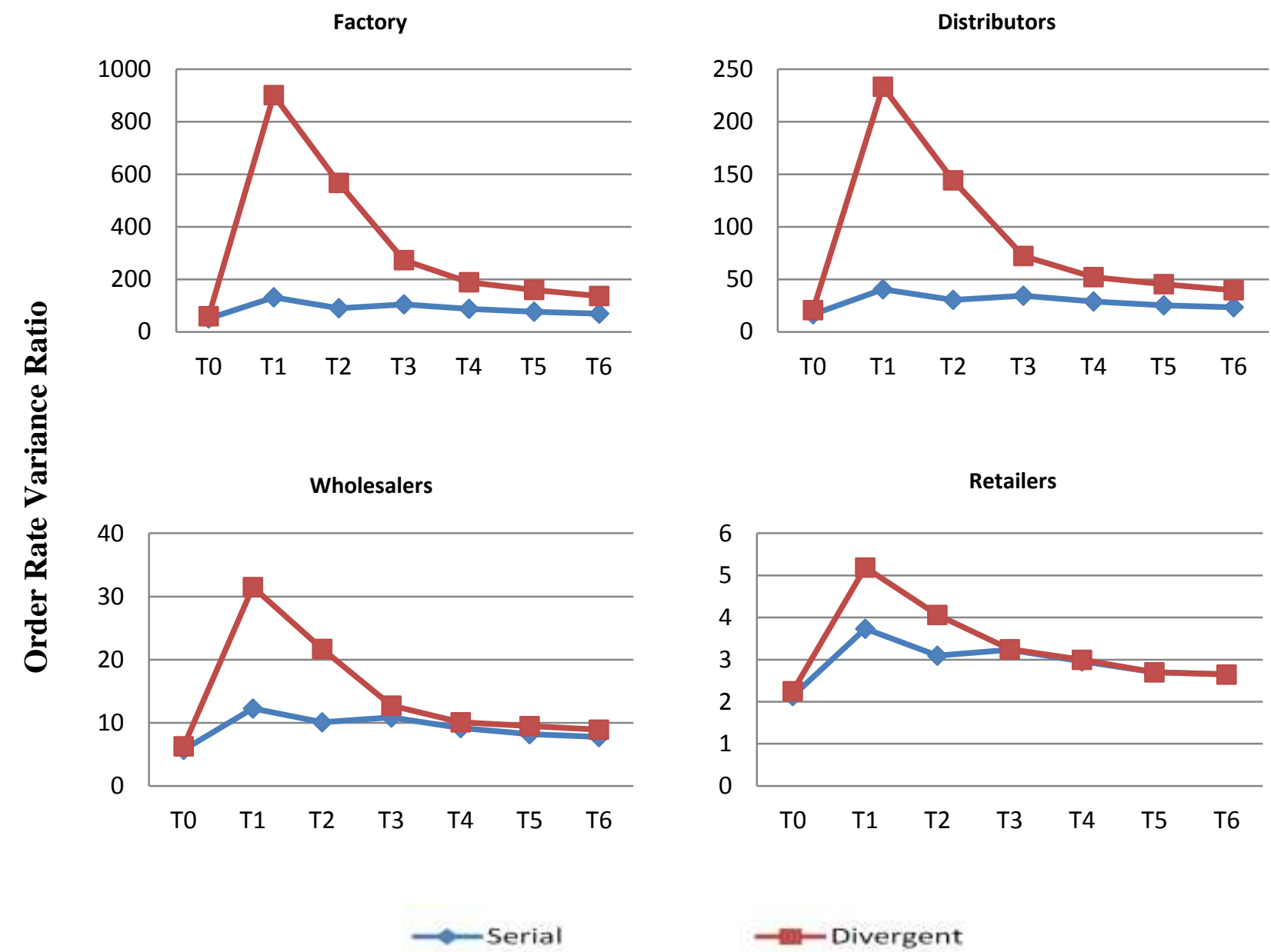

Figure 5. Evolution of $\Phi$ over time under the Shock Lens.

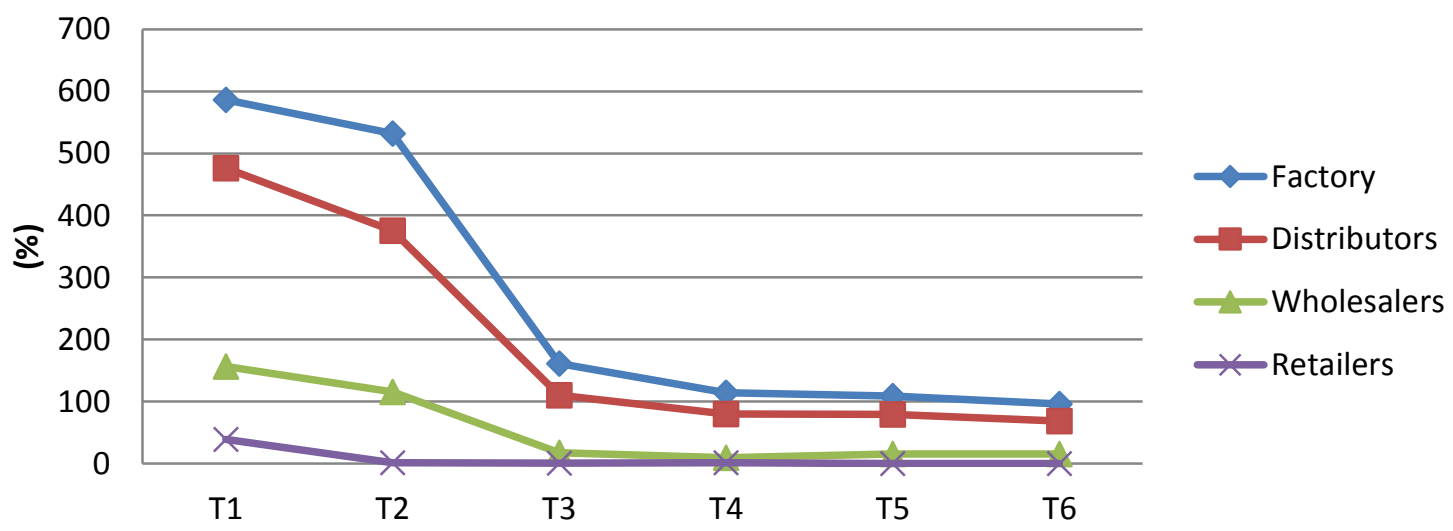

Figure 6. Divergent SCN $\Phi$ increments over the serial SCN. 

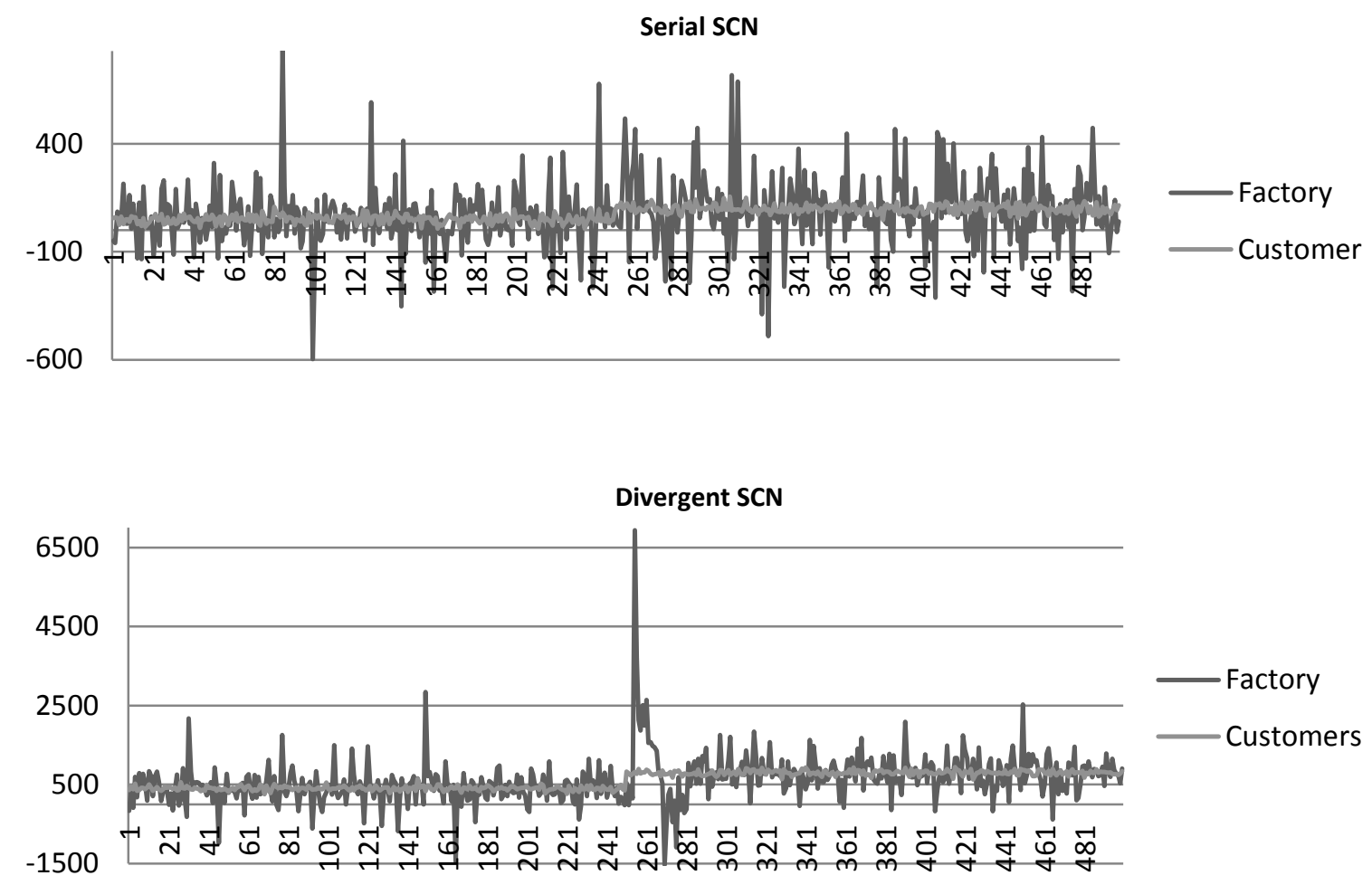

Figure 7. Factory vs end customer demand order patterns under the shock lens. 
Table 1. An overview of relevant contributions published during the Bullwhip Avoidance Phase.
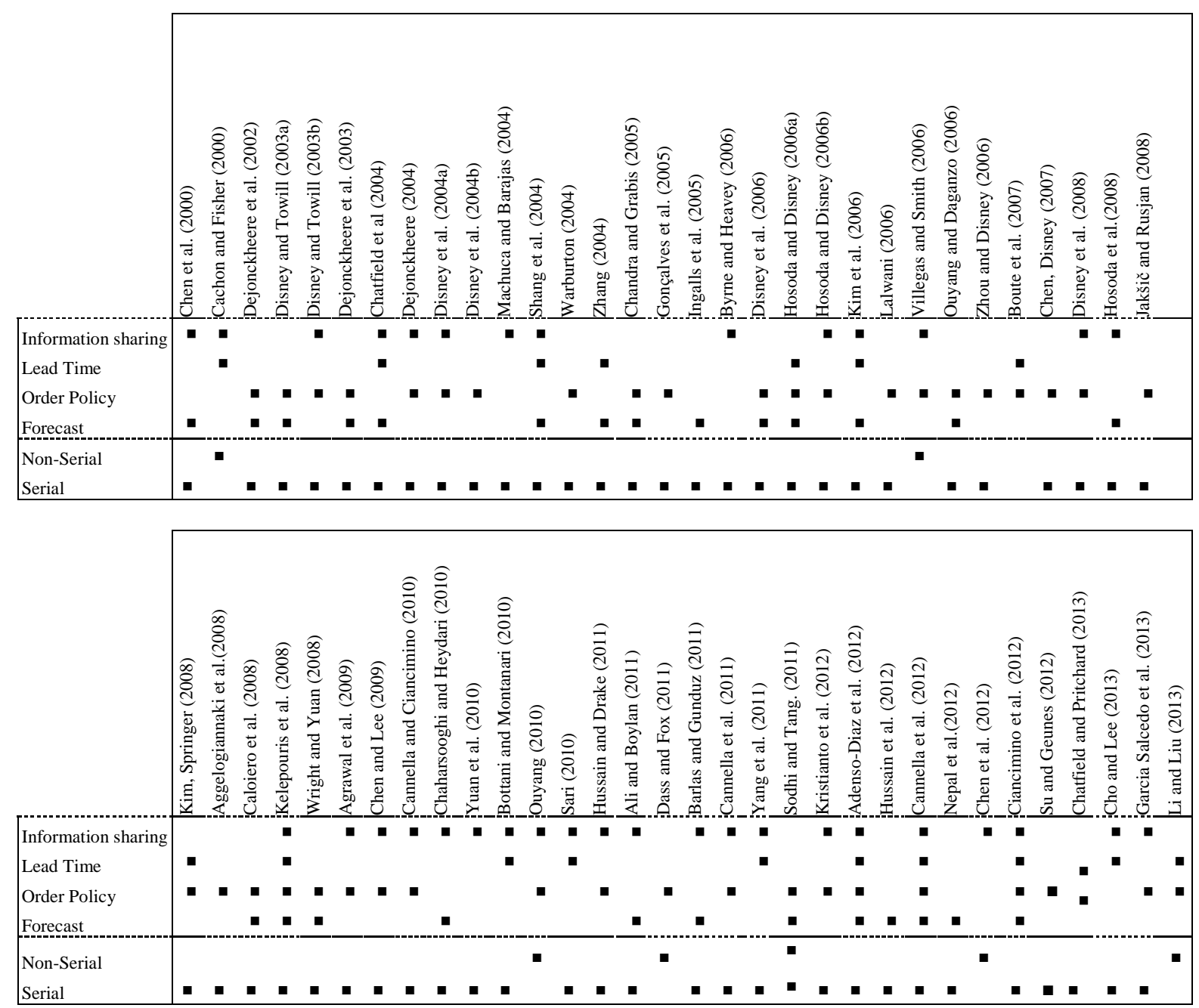

Table 2: Validation of SCOPE

\begin{tabular}{|c|c|c|c|}
\hline Echelon & Chen et al. (2000) & $\begin{array}{c}\text { Chatfield et al. (2004) } \\
\text { SISCO }\end{array}$ & $\begin{array}{c}\text { Cañizares and Framinan (2012) } \\
\text { SCOPE }\end{array}$ \\
\hline Retailer & 1.89 & 1.90 & 1.90 \\
\hline Wholesaler & 3.57 & 3.59 & 3.53 \\
\hline Distributor & 6.74 & 6.70 & 6.66 \\
\hline Factory & 12.73 & 12.84 & 12.58 \\
\hline
\end{tabular}


Table 3. Stationary response set of experiments.

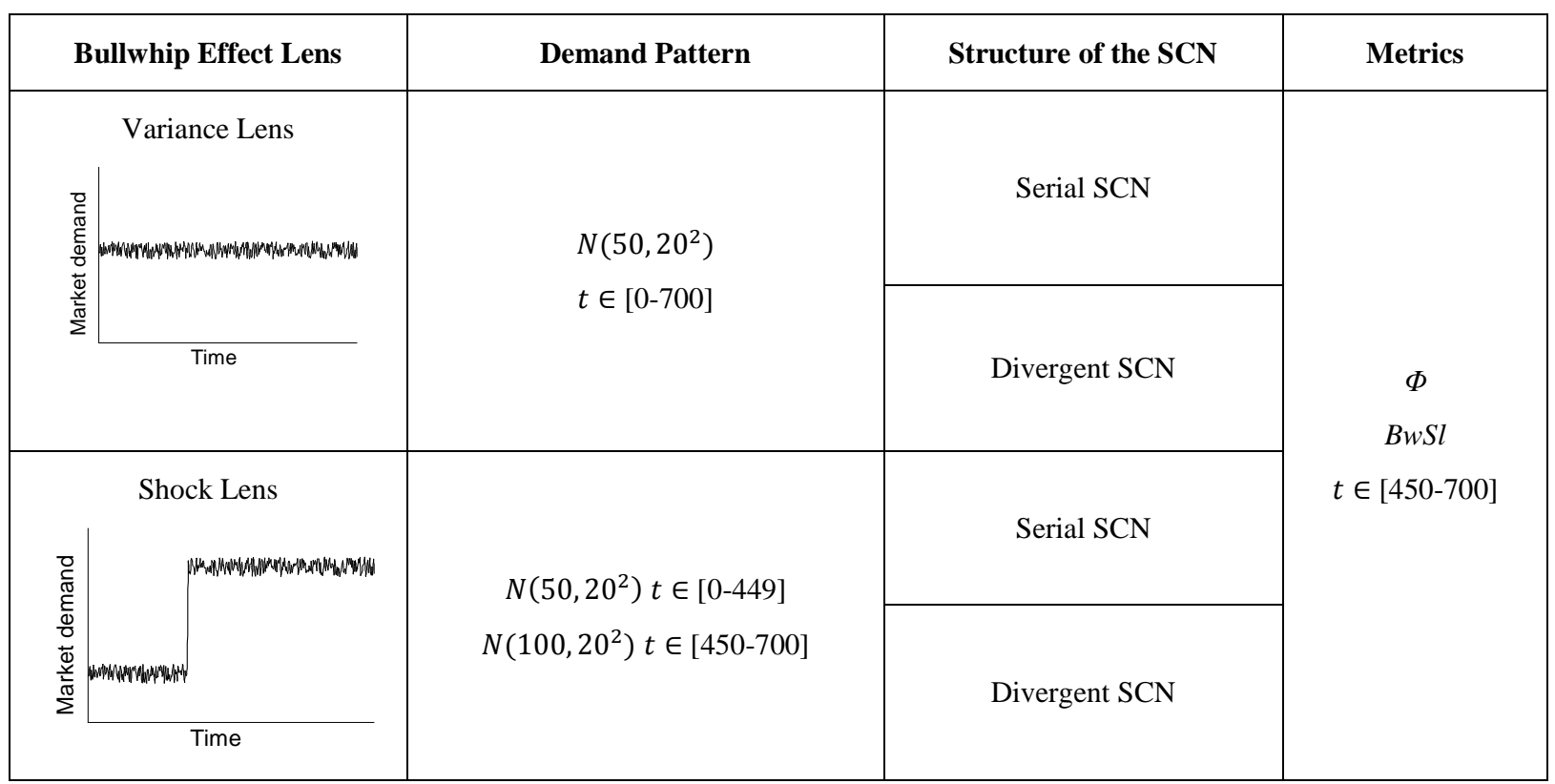

Table 4. Dynamic response set of experiments.

\begin{tabular}{|c|c|c|c|c|c|}
\hline \multicolumn{2}{|c|}{ Bullwhip Effect Lens } & Demand Pattern & Simulation Periods & Structure of the SCN & Metrics \\
\hline \multirow{6}{*}{ 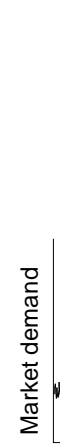 } & \multirow{3}{*}{ ock Lens } & \multirow{4}{*}{$\begin{array}{l}N\left(50,20^{2}\right) \\
t \in[0-449]\end{array}$} & T0: [200-449] & Serial/Divergent & \multirow{7}{*}{$\Phi$} \\
\hline & & & $T 1:[450-475]$ & Serial/Divergent & \\
\hline & & & $T 2:[450-500]$ & Serial/Divergent & \\
\hline & \multirow[t]{3}{*}{ 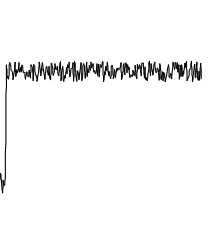 } & & T3: [450-550] & Serial/Divergent & \\
\hline & & \multirow{3}{*}{$\begin{array}{l}N\left(100,20^{2}\right) \\
t \in[450-700]\end{array}$} & T4: [450-600] & Serial/Divergent & \\
\hline & & & T5: [450-650] & Serial/Divergent & \\
\hline \multicolumn{2}{|r|}{ Time } & & T6: [450-700] & Serial/Divergent & \\
\hline
\end{tabular}


Table 5. Numeric results for $\Phi$ and $B w S l$.

\begin{tabular}{|c|c|c|c|c|c|c|c|}
\hline \multirow{2}{*}{\multicolumn{2}{|c|}{ Lens }} & \multirow{2}{*}{$\begin{array}{c}\text { SCN } \\
\text { structure }\end{array}$} & \multicolumn{4}{|c|}{$\Phi$} & \multirow{2}{*}{$B w S l$} \\
\hline & & & Retailer & Wholesaler & Distributor & Factory & \\
\hline \multirow{3}{*}{ 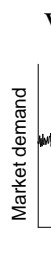 } & Variance Lens & Serial & $2.253 \pm 0.0308$ & $6.329 \pm 0.1766$ & $19.153 \pm 0.7367$ & $57.766 \pm 2.6669$ & $13.043 \pm 0.603$ \\
\hline & \multirow{2}{*}{ 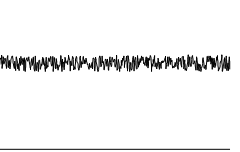 } & \multirow{2}{*}{$\begin{array}{c}\text { Divergent } \\
\Delta(\%)\end{array}$} & \multirow{2}{*}{$\begin{array}{c}2.258 \pm 0.0289 \\
\mathbf{0 . 2 2 2}\end{array}$} & $6.331 \pm 0.1695$ & $20.186 \pm 7626$ & $61.276 \pm 2.6517$ & \multirow{2}{*}{$\begin{array}{c}13.852 \pm 0.603 \\
\mathbf{6 . 2 0 3}\end{array}$} \\
\hline & & & & 0.032 & 5.393 & 6.076 & \\
\hline \multirow{4}{*}{ 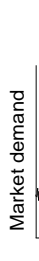 } & Shock Lens & Serial & $2.655 \pm 0.0126$ & $7.732 \pm 0.1203$ & $23.453 \pm 0.4962$ & $69.539 \pm 1.7386$ & $15.790 \pm 0.394$ \\
\hline & 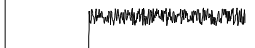 & \multirow{3}{*}{$\begin{array}{c}\text { Divergent } \\
\Delta(\%)\end{array}$} & \multirow{3}{*}{$\begin{array}{c}2.690 \pm 0.0119 \\
\mathbf{1 . 3 1 8}\end{array}$} & $8.923 \pm 0.1188$ & $39.595 \pm 0.8211$ & $136.196 \pm 2.8934$ & \multirow{3}{*}{$\begin{array}{c}30.730 \pm 0.654 \\
\mathbf{9 4 . 6 1 7}\end{array}$} \\
\hline & & & & 15.404 & 68.827 & 95.856 & \\
\hline & Time & & & & & & \\
\hline
\end{tabular}

